Revista Brasileira de Agricultura Irrigada v.8, no. 4, p.343 - 353, 2014

ISSN 1982-7679 (On-line)

Fortaleza, CE, INOVAGRI - http://www.inovagri.org.br

DOI: $10.7127 /$ rbai.v8n400246

Protocolo 246/14 - 26/04/2014 Aprovado em 25/06/2014

\title{
REPETIBILIDADE DE UM SISTEMA DE IRRIGAÇÃO POR GOTEJAMENTO SOB ENTUPIMENTO
}

Fernando Nobre Cunha ${ }^{1}$, Nelmício Furtado da Silva ${ }^{2}$, Marconi Batista Teixeira ${ }^{3}$, Pedro Henrique Ribeiro ${ }^{4}$, Luciana Minervina de Freitas Moura ${ }^{5}$ Cláudio Carvalho dos Santos ${ }^{6}$

\section{RESUMO}

Objetivou-se com este trabalho determinar uma metodologia para verificar a quantidade de gotejadores a ser avaliado sob entupimento utilizando diferentes coeficientes de uniformidade. O experimento foi conduzido em 2011, em bancada de ensaio instalada em casa de vegetação na área experimental do Instituto Federal de Educação, Ciência e Tecnologia Goiano, Câmpus Rio Verde. O delineamento experimental foi inteiramente casualizado, com quatro repetições, em esquema fatorial $4 \times 3 \times 5$, onde foram utilizados quatro coeficientes de uniformidade: CUC, CUE, CUD e CUA. Foi utilizada uma linha que comportava 130 emissores dos quais foram selecionados aleatoriamente 16, 32 e 64 gotejadores para a realização dos ensaios. Para as porcentagens de entupimentos $(0 \%, 6,25 \%$, $12,5 \%, 18,75 \%$ e $25 \%$ ), os gotejadores foram lacrados por meio do uso de adesivo plástico à saída do orifício dos mesmos. Os dados obtidos foram submetidos à análise de variância pelo teste $\mathrm{F}, 1 \%$ e $5 \%$ de probabilidade, e em caso de significância, foi realizada a análise de regressão e as médias foram comparadas entre si pelo teste Tukey a 5\% de probabilidade. O CUE, CUD e CUA demonstraram um crescimento logarítmico em função dos números de pontos observados.

Palavras-chave: uniformidade, número de pontos observados, emissores, ensaio.

\section{REPEATABILITY OF A DRIP IRRIGATION SYSTEM UNDER CLOGGING}

\footnotetext{
ABSTRACT

This study aimed to determine a methodology to verify the quantity of irrigation drippers to be evaluated under clogging using different coefficients of uniformity. The experiment was

${ }^{1}$ Mestrando em Ciências Agrárias - Agronomia, Instituto Federal Goiano - Câmpus Rio Verde, Rodovia Sul Goiana, Km 01, CEP: 75.901-170, Rio Verde - GO, e-mail: fernandonobrecunha@ hotmail.com

${ }^{2}$ Mestrando em Ciências Agrárias - Agronomia, IFGoiano - Câmpus Rio Verde, e-mail: nelmiciofurtado@gmail.com

${ }^{3}$ Eng. Agrônomo, Prof. Dr. em Agronomia, IFGoiano - Câmpus Rio Verde, e-mail: marconibt@gmail.com

${ }^{4}$ Mestre em Irrigação, Universidade Federal de Campina Grande - Campina Grande - PB, e-mail: pedroirri@gmail.com

${ }^{5}$ Mestrando em Ciências Agrárias - Agronomia, IFGoiano - Câmpus Rio Verde, e-mail: luciaminervina@yahoo.com.br

${ }^{6}$ Acadêmico de Agronomia, IFGoiano - Câmpus Rio Verde, e-mail: santos.claudiocarvalho@gmail.com
} 
conducted in 2011, in trial bench installed at greenhouse in experimental area of Instituto Federal de Educação, Ciência e Tecnologia Goiano, Câmpus Rio Verde - GO, Brazil. The experimental design was completely randomized, with four replications, in a factorial design $4 \times 3 \times 5$, where they were used four coefficients of uniformity: CUC, CUE, CUD and CUA. It was use a line that was supposed to carry 130 emitters of whom were randomly selected 16 , 32 and 64, for the carrying out of the tests Already for the levels of cloggings, the drippers were sealed $(0 \% ; 6.25 \% ; 12.5 \% ; 18.75 \%$ e $25 \%)$ through the use of adhesive plastic in the output orifice of the emitters. The obtained data were submitted to analysis of variance by the $\mathrm{F}$ test at the level of $1 \%$ to $5 \%$ of probability, and in cases of significance, regression analysis was used and the averages were compared among themselves by Tukey test at $5 \%$ probability. The CUE, CUD and AUC demonstrated a logarithmic growth depending on the number of points.

Keywords: uniformity, number of points, emitters, test

\section{INTRODUÇÃO}

Uma característica inerente aos métodos de irrigação localizada é a pequena área de passagem da água nos emissores. Em função dos pequenos diâmetros do orifício. A obstrução dos emissores parece ser o maior problema associado à operação de irrigação por gotejamento (BRAUER, 2010).

O entupimento pode ser parcial, reduzindo a uniformidade de aplicação, ou total, interrompendo por completo o funcionamento do sistema, causando sérios problemas às culturas, devido à deficiência hídrica (CARARO, 2004). O entupimento de gotejadores prejudica o funcionamento geral do sistema de irrigação, afetando suas características de operação e exigindo manutenções mais frequentes. Comumente, a obstrução diminui a uniformidade de aplicação de efluente de sistemas de irrigação localizada (LIU; HUANG, 2009).

Busato et al. (2012) comentam que o ferro e o manganês, em elevados teores, são os principais causadores das obstruções dos emissores em sistemas de irrigação localizada.

Estudos realizados por Ribeiro et al. (2008), também relatam sobre problemas de entupimentos devido a problemas biológicos. Estes indicaram que a ocorrência de entupimentos nos gotejadores era devido à alta concentração de algas presente na água que abastecia o sistema de irrigação localizada por gotejamento, que foram causados pela presença de fósforo, cuja concentração era de $1 \mathrm{mg} \mathrm{L}^{-1}$.

De acordo com estudos sobre a influência da qualidade da água no entupimento de sistemas de irrigação localizada, realizados por Franco e Hernandez (2009), os autores encontraram valores com maiores médias de $\mathrm{pH}$ entre 7,5 e 7,3, respectivamente, que indicam risco moderado de entupimento.

Entre as práticas mais aceitas ambientalmente para a diminuição do entupimento se incluem a sedimentação, a filtração, o aumento da pressão de serviço e a limpeza das linhas laterais com água (PUIG-BARGUÉS et al., 2010). 
Batista et al. (2013) trabalhando com água residuária de suinocultura, verificaram que as características sólidos suspensos, ferro total e população bacteriana representaram risco severo de entupimento de gotejadores e que as porcentagens de entupimento dos gotejadores podem ser menores em função do menor tempo de funcionamento do equipamento para aplicação sustentável da água residuária da suinocultura.

Para Vieira et al. (2004b) vários fatores podem comprometer a uniformidade de distribuição de água em sistemas localizados destacando-se, entre eles, o entupimento ou o desequilíbrio de vazão dos emissores. É possível que a medição em apenas 16 pontos seja suficiente para a determinação da uniformidade de aplicação de água pelo sistema e que em certas situações, a avaliação acima de 16 gotejadores por setor possa ser muito laboriosa (MANTOVANI, 2001; VIEIRA et al., 2004a); no entanto, quando sob entupimento essa quantidade de emissores avaliados pode vir a ser insuficiente para demonstrar a real condição do sistema.

Objetivou-se com este trabalho definir uma metodologia para verificar a quantidade de gotejadores a ser avaliada sob entupimento, utilizando diferentes coeficientes de uniformidade.

\section{MATERIAL E MÉTODOS}

O experimento foi conduzido em 2011, em uma bancada de ensaio instalada em casa de vegetação na área experimental do Instituto Federal de Educação, Ciência e Tecnologia
Goiano, Câmpus Rio Verde. A casa de vegetação é constituída de cobertura de filme plástico polietileno transparente, de 150 micras e laterais fechadas, com tela tipo sombrite com $30 \%$ de interceptação.

O delineamento experimental foi inteiramente casualizado, com quatro repetições, em esquema fatorial 4 x 3 x 5, sendo 4 dispersões de partículas sólidas (diâmetro interno), as quais foram denominadas pelo respectivo coeficiente de uniformidade, utilizado para determinar a uniformidade: coeficiente de uniformidade de Christiansen (CUC), coeficiente de uniformidade estatístico (CUE), coeficiente de uniformidade de distribuição (CUD), coeficiente de uniformidade absoluto (CUA) (Figura 1). A linha comportava 130 emissores dos quais foram selecionados aleatoriamente 16, 32 e 64 emissores, para a realização dos ensaios. Já para as porcentagens de entupimentos $(0 \%$; $6,25 \% ; 12,5 \% ; 18,75 \%$ e $25 \%$ ), os gotejadores foram lacrados por meio do uso de adesivo plástico à saída do orifício dos emissores, conforme metodologia adotada por Bralts et al. (1987), e a escolha dos emissores a serem lacrados também se deu de forma aleatória. O procedimento de aplicação de água consistiu de 6 h diária.

CUC

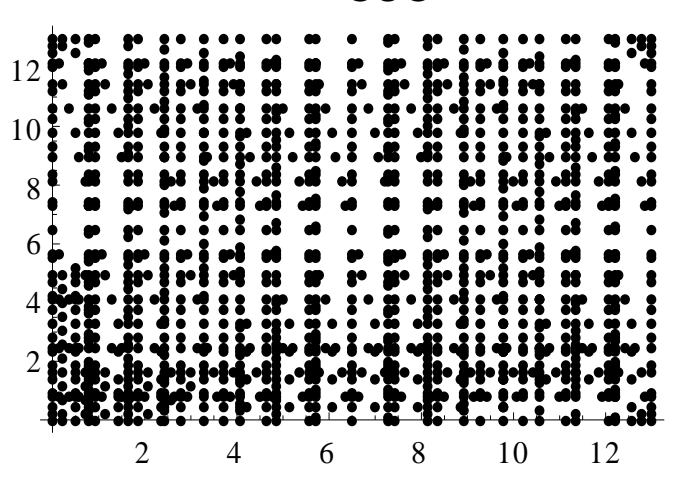




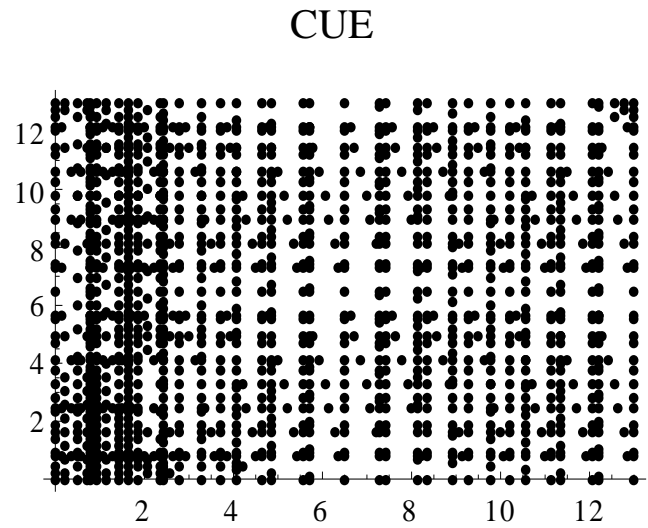

CUD

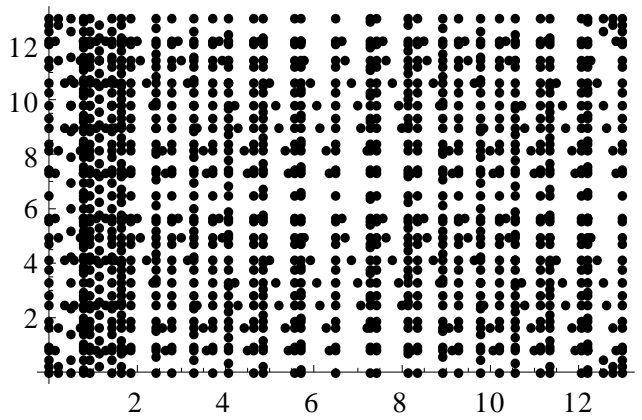

CUA

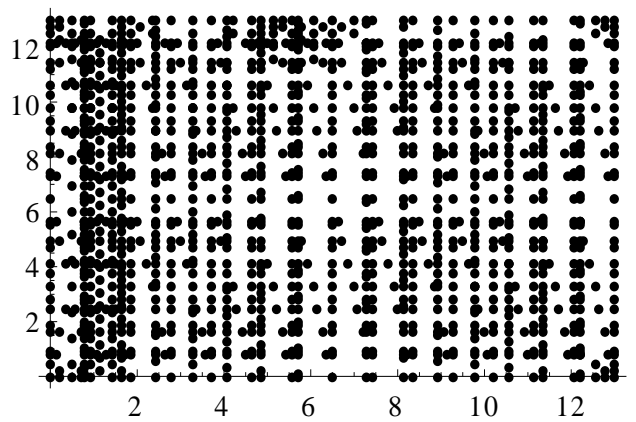

Figura 1. Dispersão das partículas sólidas (diâmetro interno).

Foi utilizado um modelo de tubo gotejador com vazão nominal de $1 \mathrm{~L} \mathrm{~h}^{-1}$, diâmetro nominal de $16 \mathrm{~mm}$, diâmetro interno de $13 \mathrm{~mm}$, pressão de operação de 100 a 350 $\mathrm{kPa}$ e espaçamento entre emissores de $0,8 \mathrm{~m}$. O sistema de pressurização utilizado no experimento foi composto por uma motobomba centrífuga.

$\mathrm{Na}$ entrada de cada linha gotejadora foi instalada uma tomada de pressão, permitindo que a cada medição de vazão a pressão fosse checada e, se necessário, ajustada à preestabelecida. Para isso, foi utilizado um manômetro de Bourdon com faixa de leitura de 0 a $4 \mathrm{Kgf} \mathrm{cm}^{-2}$.

A vazão foi medida para os totais de 16 , 32 e 64 gotejadores na linha lateral, para deste modo ser calculada a uniformidade de distribuição de água no sistema de irrigação por gotejamento.

O procedimento para a realização da leitura de vazão consistiu na pressurização do sistema, estabilização da pressão em $150 \mathrm{kPa}$ (+/- $5 \mathrm{kPa})$ no início da linha gotejadora, posicionamento dos coletores sob os respectivos gotejadores com $3 \mathrm{~s}$ de defasagem e retirada dos coletores com a mesma sequência e defasagem de tempo após 5 min de coleta.

Foi utilizado o método gravimétrico para a determinação do volume coletado de cada emissor, expressando-se os valores de vazão em $\mathrm{L} \mathrm{h}^{-1}$, utilizando para tal uma balança de precisão certificada (OHAUS) com precisão de $0,01 \mathrm{~g}$.

O monitoramento da vazão dos gotejadores $\left(\mathrm{L} \mathrm{h}^{-1}\right)$ calculada pela equação 1 permitiu a obtenção da vazão média dos gotejadores em cada ensaio.

$$
\mathrm{q}=\frac{\mathrm{M}}{1000 \times \mathrm{t}} 60
$$

em que:

$\mathrm{q}$ - vazão do gotejador, $\mathrm{L} \mathrm{h}^{-1}$;

M - massa de água coletada, g; e

$\mathrm{t}$ - tempo de coleta, min.

Depois de tabulados os dados de vazão, foram efetuados os cálculos de uniformidade de aplicação de água pelos métodos mais utilizados na literatura, destacados nas equações: 


$$
\mathrm{CUC}=100\left\{1-\frac{\sum_{\mathrm{i}=1}^{\mathrm{n}}\left|\mathrm{X}_{\mathrm{i}}-\overline{\mathrm{X}}\right|}{\mathrm{n} \cdot \overline{\mathrm{X}}}\right\} \quad \begin{aligned}
& \text { variância pelo teste } \mathrm{F} \text { aos níveis de } 1 \% \text { e } 5 \% \text { de } \\
& \text { probabilidade, e em casos de significância, foi } \\
& \text { realizada a análise de regressão e as médias } \\
& \text { foram comparadas entre si pelo teste Tukey a } \\
& 5 \% \text { de probabilidade. }
\end{aligned}
$$$$
\mathrm{CUE}=100\left(1-\frac{\mathrm{S}}{\overline{\mathrm{X}}}\right)
$$$$
\mathrm{CUD}=100\left(\frac{\mathrm{X}_{25 \%}}{\overline{\mathrm{X}}}\right)
$$$$
\mathrm{CUA}=50\left(\frac{\mathrm{X}_{25 \%}}{\overline{\mathrm{X}}}+\frac{\overline{\mathrm{X}}}{\mathrm{X}_{12,5 \%}}\right)
$$

em que:

CUC - coeficiente de uniformidade de Christiansen, em \%;

CUE - coeficiente de uniformidade estatístico, em \%;

CUD - coeficiente de uniformidade de distribuição, em \%;

CUA - coeficiente de uniformidade absoluto, em \%;

$\mathrm{X}_{\mathrm{i}}$ - vazão de cada gotejador, em $\mathrm{L} \mathrm{h}^{-1}$;

$\overline{\mathrm{X}}$ - vazão média dos gotejadores, em $\mathrm{L} \mathrm{h}^{-1}$;

n - número de gotejadores observados;

S - desvio-padrão dos dados de vazão, em L $\mathrm{h}^{-1}$;

$\mathrm{X}_{25 \%}$ - média de $25 \%$ do total de gotejadores, com as menores vazões, em $\mathrm{L} \mathrm{h}^{-1}$; $\mathrm{e}$ $\mathrm{X}_{12,5 \%}$ - média de $12,5 \%$ do total de gotejadores, com as maiores vazões, em $\mathrm{L} \mathrm{h}^{-1}$.

Para a avaliação dos coeficientes de uniformidade utilizou-se as classificações dos valores encontrados propostas na literatura para cada método: CUC, CUE, CUD e CUA (MANTOVANI, 2001; ASAE, 2003). Os dados obtidos foram submetidos à análise de

\section{RESULTADOS E DISCUSSÃO}

A dispersão das partículas sólidas no diâmetro interno tem maior influência na uniformidade conforme diminui o número de pontos avaliados e aumenta a obstrução total, sendo a uniformidade bastante variável quando sob obstrução parcial (Figura 1).

A vazão média tornou-se mais acurada com o aumento do número de pontos observados, consequentemente a maior precisão foi obtida com o número máximo igual a 64 . Quanto maior o número de gotejadores avaliado melhor será a avaliação do sistema, devido principalmente a uma melhor interpretação proveniente de uma maior representatividade destes valores. Isto também é favorecido por ser possível verificar a distribuição dos valores de vazão ao longo da linha lateral, o seu comportamento e em que intervalo estes valores estão concentrados (Figura 2), entretanto a avaliação acima de 32 pontos pode torna-se muito trabalhosa. Mesmo assim, ainda é interessante procurar realizar a avaliação no maior número possível de gotejadores, pois em um sistema onde esteja ocorrendo o entupimento parcial ou total a chance de encontrá-los diminui com a redução da quantidade de números de pontos avaliados. 


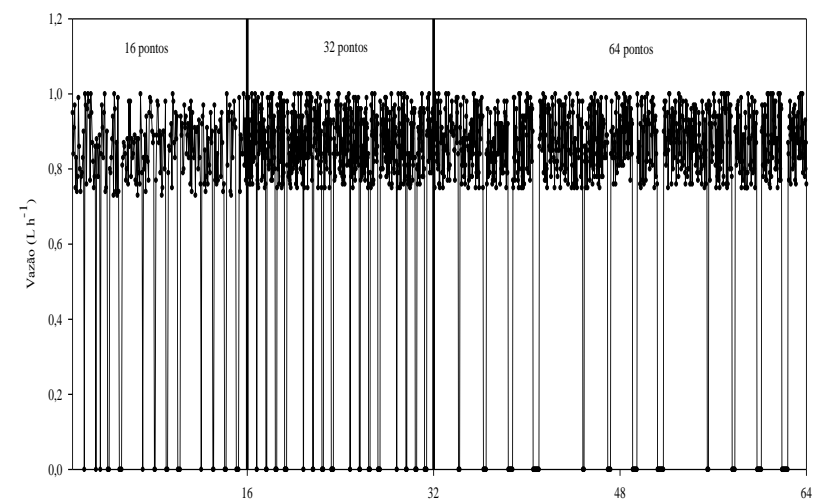

Nümero de pontos

Figura 2. Vazões obtidas para os números de pontos avaliados de 16 (<16), 32 (entre 16 e 32) e 64 (>32), junto com as porcentagens de entupimento.

O gotejador avaliado indicou decréscimo de vazão, conforme foi aumentando o percentual de gotejadores entupidos, como Souza et al. (2006) verificaram na maioria dos modelos de gotejadores o mesmo comportamento, sendo observado por estes, no entanto, o contrário em apenas um modelo de gotejador, onde a vazão aumentou à medida que mostrou problemas de entupimento.

A maior quantidade de pontos avaliados evita que haja problemas com subestimação ou superestimação do valor médio da vazão, da variação (CV) e da uniformidade, por conseguinte, ajusta os valores próximos ao real, garantindo um conhecimento mais profundo do sistema, reduzindo desperdícios e gastos, o que implica em uma fidedigna estimativa do desempenho da irrigação, entretanto apresenta a desvantagem de tornar a avaliação do sistema mais complicada e onerosa.

A avaliação de desempenho dos sistemas de irrigação é expressa pelos parâmetros de uniformidade, eficiência e grau de adequação. A uniformidade está associada à variabilidade da quantidade de irrigação; a eficiência expressa a razão entre as quantidades de água envolvidas no processo de irrigação; e o grau de adequação expressa o quanto o sistema de irrigação satisfaz, em termos de fração da área irrigada (GRAH et al., 2008).

Os métodos de cálculo de coeficientes, as quantidades de pontos avaliados e níveis entupimento tiveram efeito sobre a uniformidade. A interação entre métodos de cálculo e quantidades de pontos, e entre métodos de cálculo e níveis de entupimento influenciaram o percentual da uniformidade. Quanto as quantidades de pontos versus níveis de entupimento, e estes versus os métodos de cálculo não foram significativas.

As médias de CUA, CUE e CUD para todas as quantidades de pontos avaliados são significativamente menores do que a do CUC. Com 16 e 32 gotejadores avaliados o CUA e o CUE foram iguais, enquanto que com 64 gotejadores o CUE foi maior do que o CUA. Carvalho et al. (2006) obteve valor do coeficiente de uniformidade absoluta (CUA) igual a $72,68 \%$, sendo classificado como regular, valores estes próximos aos verificados para todas as quantidades de pontos avaliados para este coeficiente, com média de $62,49 \%$.

As médias do CUC, CUA e CUE para todas as quantidades de pontos avaliados são significativamente maiores do que a do CUD (Tabela 1), sendo em média 1,4 vez menor do que estes. O CUC e o CUD apresentaram valores bastante destoantes enquanto que o CUA e o CUE mostraram valores intermediários mais equiparados ao do CUD, logo, foram obtidas classificações distintas para o CUC, 
considerada razoável, e para o CUE, o CUA e o CUD ruim.

Tabela 1. Coeficientes de uniformidade relacionados aos números de pontos avaliados.

\begin{tabular}{ccccccc}
\hline Coeficientes & \multicolumn{6}{c}{ Ne } \\
\cline { 2 - 7 } uniformidade & 16 pontos & 32 pontos & 64 pontos \\
\hline CUC & 72,70 & a & 73,04 & a & 72,95 & a \\
CUA & 62,26 & b & 62,70 & b & 62,50 & c \\
CUE & 62,12 & b & 63,05 & b & 63,28 & b \\
CUD & 46,81 & c & 47,42 & c & 47,13 & d \\
\hline
\end{tabular}

*Média com a mesma letra minúscula na coluna entre os métodos não indica diferença significativa pelo teste Tukey, a 5\% de probabilidade.

As médias de CUC, CUA, CUE e CUD em todas as porcentagens de entupimentos são significativamente diferentes (Tabela 2). O CUC, CUA, CUE e CUD com $0 \%$ de entupimento foram todos classificados como excelente; com $6,25 \%$ de entupimento o CUC foi classificado como bom, o CUA e CUE como razoável e o CUD como bom; com $12,5 \%$ de entupimento o CUC foi classificado como razoável, o CUA, CUE e CUD como ruim; com $18,75 \%$ de entupimento o CUC foi classificado como ruim, o CUA, CUE e CUD como inaceitáveis e com $25 \%$ de entupimento todos foram classificados como inaceitáveis.

Martins et al. (2010) utilizando irrigação com água ferruginosa, obtiveram a seguinte classificação excelente no início das avaliações (CUC igual a 95,8\%), mas apresentou redução no valor de CUC de $23 \%$, passando a ser classificado como razoável na última avaliação (CUC igual a 73,75\%). Para o CUD o valor médio foi de $92,65 \%$, classificação excelente, mas na última avaliação o valor médio foi de $64,65 \%$, classificação ruim, indicando uma redução de $30,2 \%$.
Tabela 2. Coeficientes de uniformidade relacionados às porcentagens de entupimento.

\begin{tabular}{crrrrrrrrrrrr}
\hline $\begin{array}{c}\text { Coeficientes } \\
\text { de } \\
\text { uniformidade }\end{array}$ & \multicolumn{10}{c}{ Entupimento (\%) } \\
\cline { 2 - 9 } CUC & 92,57 & a & 84,64 & a & 74,76 & A & 62,50 & a & 50,00 & a \\
& & & & & & & & & & \\
CUA & 88,79 & c & 76,79 & b & 63,88 & B & 49,27 & c & 33,71 & c \\
& & & & & & & & & & \\
CUE & 91,23 & b & 72,09 & c & 60,36 & C & 49,99 & b & 40,41 & b \\
& & & & & & & & & & \\
CUD & 89,10 & c & 70,09 & d & 50,03 & D & 26,38 & d & 0,00 & d
\end{tabular}

*Média com a mesma letra minúscula na coluna entre os métodos não indica diferença significativa pelo teste Tukey, a 5\% de probabilidade.

Com entupimento de $18,75 \%$, os valores de CUC praticamente não variaram, ficando em entorno de 62,5\%. O mesmo aconteceu com $25 \%$ de entupimento onde se verificou que a uniformidade ficou fixa em $50 \%$, bem como os valores do CUD, que a partir de $25 \%$ de entupimento não apresentaram variação alguma, indicando $0 \%$ de uniformidade, conforme o esperado, pois o método considera a média de $25 \%$ do total de gotejadores, com as menores vazões.

Silva et al. (2012) observaram as menores uniformidades de distribuição quando o esgoto doméstico foi tratado com filtro digestor associado a uma lagoa de estabilização, apresentando, na terceira avaliação CUD de 45,7\% e CUE de $84 \%$, e que a menor remoção dos sólidos suspensos totais por este método deve ter sido a principal causa para as baixas uniformidades observadas. Assim essa diferença verificada por eles entre o CUE e CUD ficou em torno de $38,3 \%$, próxima da máxima diferença verificadas entre estes coeficientes na porcentagem de entupimento de $25 \%$ que foi de aproximadamente $40 \%$ (Tabela 2).

$\mathrm{O}$ entupimento tem alto impacto sobre os coeficientes de uniformidade e consequentemente sobre a própria uniformidade de aplicação, entretanto ambos os coeficientes tenderam a subestimar o valor real da uniformidade. 
Ribeiro e Paterniani (2013) observaram que ocorreu uma diminuição de uniformidade de distribuição de água ao longo do tempo, entre a primeira e a quarta etapa para os dois sistemas de filtragem, indicando que houve uma tendência de entupimento dos gotejadores, sendo que a diminuição da uniformidade foi mais acentuada entre a terceira e a quarta etapa.

Os coeficientes de uniformidade adequaram-se ao modelo linear, assim a uniformidade diminuiu com o aumento da porcentagem de entupimento. A uniformidade de distribuição de água às plantas está diretamente ligada ao problema de entupimento de gotejadores (AIROLDI, 2007), onde uma pequena porcentagem de emissores entupidos pode reduzir de forma significativa a uniformidade de aplicação de água.

A maior queda na uniformidade de $0 \%$ para $25 \%$ de entupimento foi de $89 \%$, verificada no CUD em todas as quantidades de pontos avaliados, e a menor de aproximadamente $42 \%$ no CUC na quantidade de 16 pontos (Figura 3A). O CUA apresentou um decréscimo mais constante de uma porcentagem de entupimento para a outro, em média de $13,8 \%$, principalmente na quantidade de pontos observados de 64 (Figura 3C). O CUE, quando considerado a partir de $6,25 \%$ de entupimento até $25 \%$, apresentou uma diferença de $10,5 \%$ na medição de 32 pontos (Figura 3B). O CUE e o CUA decresceram similarmente ao CUC, indicando um comportamento mais estável do que o verificado no CUD, que apresentou diferenças mais expressivas por supervalorizar os entupimentos.

Variações não da mesma ordem, mas ainda significativas de decréscimo do CUD foram observadas por Batista et al. (2010) em estudos avaliando a influência da aplicação de esgoto doméstico tratado via gotejamento. Após $120 \mathrm{~h}$ de funcionamento foram verificadas reduções nos valores do CUD, da ordem de $10,58 \%$, os quais atribuíram a redução do
CUD ao entupimento parcial ou total dos gotejadores.

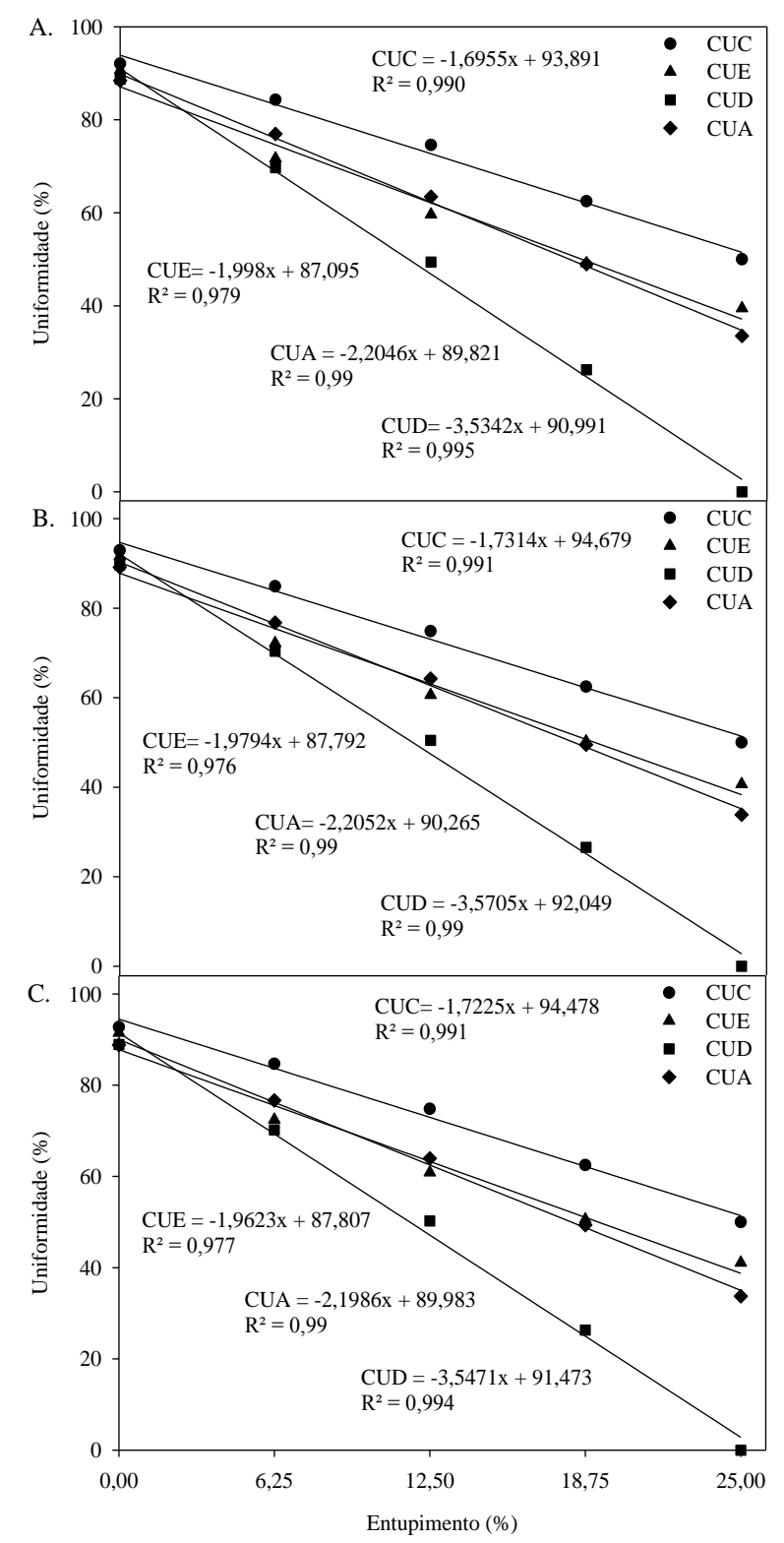

Figura 3. Uniformidade de aplicação em função da porcentagem de entupimento, para 16 (A), 32 (B) e 64 (C) pontos observados.

O CUC não apresentou diferença em função das quantidades de pontos avaliados. Deste modo, este coeficiente se mostrou pouco sensível às variações de vazãos verificadas nas diferentes quantidades de pontos avaliados, indicando que pode ser dispendioso, além de ineficaz o aumento da quantidade de pontos quando se procura utilizar este coeficiente. Por outro lado, isto pode ser interessante por não 
haver a necessidade de uma grande quantidade de pontos para a determinação da uniformidade, o que pode facilitar o manejo, mas não é garantia de que não se possa incorrer em erros.

O CUE, CUD e CUA demonstraram um crescimento logarítmico em função da quantidade de pontos avaliados. O valor máximo para ambos foi verificado na medição de 64 gotejadores, sendo estes iguais a $63,4 \%, 47,4 \%$ e $62,7 \%$ respectivamente, o que reforça de maneira significativa a importância de avaliar um número maior de gotejadores (Figura 4).

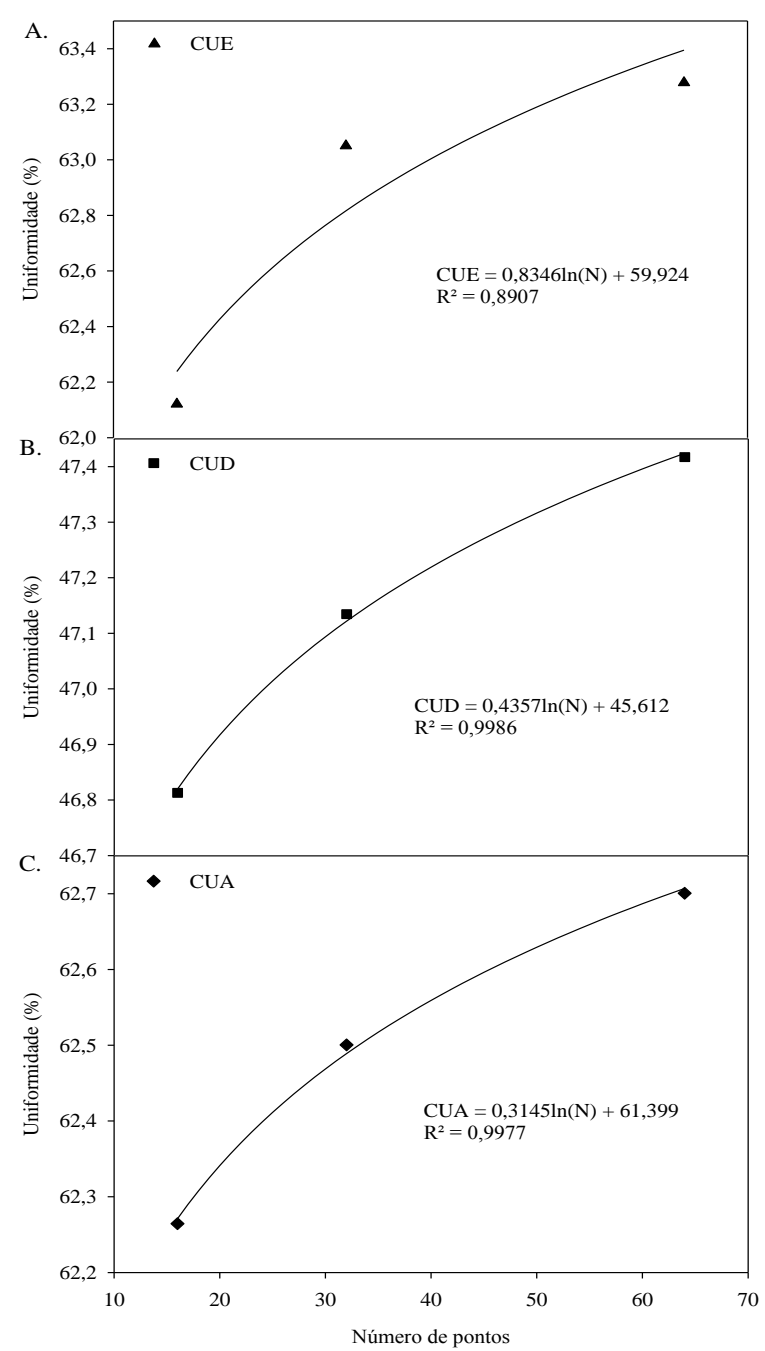

Figura 4. Uniformidade de aplicação em função da quantidade de pontos avaliados, para o CUE (A), o CUD (B) e o CUA (C).

A avaliação em uma ou mais linhas laterais pode indicar diferenças ainda mais elevadas na uniformidade, pois a probabilidade de encontrar os gotejadores entupidos é dada pela quantidade de pontos avaliados dividida pelo número total de gotejadores da linha lateral (NP/NT). Então ao utilizar uma pequena quantidade de gotejadores avaliados, mesmo sendo menor a chance de encontrar um número alto de entupimento em relação ao número de pontos avaliados, ela não pode ser descartada. Deste modo como o entupimento tem uma influência considerável sobre a uniformidade, isto será determinante nessas diferenças que podem variar entre $42 \%$ e $89 \%$, dependendo do coeficiente utilizado. Assim sendo quando for encontrado um grande número de gotejadores entupidos, relativos a uma quantidade de pontos avaliados, é recomendado aumentar este número de pontos para garantir que esse percentual de entupimento está de acordo ou não. O mesmo vale para a uniformidade.

O acréscimo na quantidade de gotejadores avaliados, pode não ser viável do ponto de vista prático. Torna-se assim mais interessante o estabelecimento de uma quantidade maior de gotejadores a serem avaliados já na implantação do sistema. Deve ser evitada a adoção de um número fixo de gotejadores a serem avaliados, ao invés disso, deve-se dar preferência a um número variável destes a serem medidos, em casos que haja risco de entupimento, isto tanto para facilitar quanto para garantir uma avaliação mais condizente com a realidade.

\section{CONCLUSÃO}

A chance de encontrar o entupimento parcial ou total diminui conforme diminui a quantidade de pontos avaliados. 
O CUE, o CUD e o CUA demonstraram um crescimento logarítmico em função da quantidade de pontos avaliados.

A dispersão das partículas sólidas no diâmetro interno tem maior influência na uniformidade conforme diminui o número de pontos avaliados e aumenta a obstrução total, sendo a uniformidade bastante variável quando sob obstrução parcial.

\section{AGRADECIMENTOS}

Os autores agradecem ao Ministério da Ciência e Tecnologia (MCT), ao Conselho Nacional de Desenvolvimento Científico e Tecnológico (CNPq) e à Coordenação de Aperfeiçoamento de Pessoal de Nível Superior (Capes), pelo apoio financeiro e estrutural.

\section{REFERÊNCIAS BIBLIOGRÁFICAS}

AIROLDI, R. P. S. Análise do desempenho de gotejadores e da prevenção do entupimento com água residuária. Tese Doutorado. (Irrigação e Drenagem), Escola Superior de Agricultura "Luiz de Queiroz", Universidade de São Paulo, Piracicaba, 2007. 76 p.

$\begin{array}{llr}\text { AMERICAN } & \text { SOCIETY } & \text { FOR } \\ \text { AGRICULTURAL } & \text { ENGINEERS. ASAE } \\ \text { EP405.1: design and installation of } \\ \text { microirrigation systems. St. Joseph, 2003. } 6 \text { p. }\end{array}$

BATISTA, R. O.; OLIVEIRA, R. A.; SANTOS, D. B.; OLIVEIRA, A. F. M.; AZEVEDO, C. A. V.; MEDEIROS, S. S. Obstrução e uniformidade de aplicação em sistemas de irrigação por gotejamento aplicando-se efluente da suinocultura. Revista brasileira engenharia agrícola ambiental. v.17, $n^{\circ} .7$ Campina Grande Jul. 2013, 15p.

BATISTA, R. O.; SOUZA, J. A. R.; FERREIRA, D. C. Influência da aplicação de esgoto doméstico tratado no desempenho de um sistema de irrigação. Revista Ceres, v.57, p.18-22, 2010.

BRALTS, V. F., EDWARD, D. M.; WU, I. P. Drip irrigation design and evaluation based on the statistical uniformity concept. In: HILLEL, D. Advances in Irrigation, Academic Press, Orlando, v.4, p. 67-117, 1987.

BRAUER, R. L. Dinâmica de entupimento de gotejadores em função da aplicação de água rica em ferro. Tese Doutorado. Esalq, Botucatu. 2010.

BUSATO, C. C. M.; SOARES, A. A.; RAMOS, M. M.; REIS, E. F.; BUSATO, C. Dicloroisocianurato na prevenção do entupimento devido ao uso de águas ferruginosas em sistemas de irrigação por gotejamento. Semina: Ciências Agrárias, Londrina, v.33, n.1, p.49-56, 2012.

CARARO, D. C. Manejo de irrigação por gotejamento para aplicação de água residuária visando a minimização do entupimento de emissores. Tese Doutorado. (Irrigação e Drenagem), Escola Superior de Agricultura "Luiz de Queiroz", Universidade de São Paulo, Piracicaba, 2004. 130 p.

CARVALHO, C. M.; ELOI, W. M.; LIMA, S. C. R. V.; PEREIRA, J. M. G. Desempenho de um sistema de irrigação por gotejamento na cultura da goiaba. Irriga, Botucatu, v. 11, n. 1, p. 36-46, janeiro-março, 2006.

FRANCO, R. A. M.; HERNANDEZ, F. B. T. Qualidade da água para irrigação na microbacia do Coqueiro, Estado de São Paulo. Revista Brasileira de Engenharia Agrícola e 
Ambiental, Campina Grande, v.5, n.9, p.382385, 2009.

GRAH, V. F.; SOCCOL, O. J.; ULLMANN, M. N.; RODRIGUES, L. N. Influência do tempo de uso no desempenho de sistema de irrigação localizada por gotejamento. Universidade do Estado de Santa Catarina, Centro de Ciências Agroveterinárias. Embrapa Cerrados. Planaltina, DF. 2008.

LIU, H.; HUANG, G. Laboratory experiment on drip emitter clogging with fresh water and treated sewage effluent. Agricultural Water Management, v.96, p.745-756, 2009.

MANTOVANI, E. C. Avalia: Programa de Avaliação da Irrigação por Aspersão e Localizada. Viçosa, MG: UFV, 2001.

MARTINS, C. C.; SOARES, A. A.; RAMOS, M. M.; REIS, E. F. Aplicação de cloro orgânico no tratamento de tubogotejador utilizado na irrigação com água ferruginosa. Acta Science, Agronomy. vol.32 no.1 Maringá Jan./Mar. 2010.

PUIG-BARGUÉS, J.; ARBAT, G.; ELBANA, M.; DURAN-ROS, M.; BARRAGÁN, J.; RAMÍREZ DE CARTAGENA, F.; LAMM, F. R. Effect of flushing frequency on emitter clogging in microirrigation with effluents. Agricultural Water Management, v.97, p.883-891, 2010.

RIBEIRO, T. A. P.; PATERNIANI, J. E. S.; COLETTI, C. Chemical treatment to unclogg dripper irrigation systems due to biological problems. Scientia Agrícola, Piracicaba, v.65, n.1, p.1-9, 2008.

RIBEIRO, T. A. P.; PATERNIANI, J. E. S. Comparação de elementos filtrantes no grau de obstrução em irrigação por gotejamento. Engenharia Agrícola, Jaboticabal, v.33, n.3, p.15, 2013.

SILVA, L. P.; SILVA, M. M.; CORREA, M. M.; SOUZA, F. C. D.; SILVA, E. F. F. Desempenho de gotejadores autocompensantes com diferentes efluentes de esgoto doméstico. Revista brasileira de engenharia agrícola ambiental. Campina Grande, v.16, n.5, p. 480486, 2012.

SOUZA, J. A. A.; CORDEIRO, É. A.; COSTA, É. L. Aplicação de hipoclorito de sódio para recuperação de gotejadores entupidos em irrigação com água ferruginosa. Revista brasileira engenharia agrícola ambiental. 2006, vol.10, n.1, p. 5-9.

VIEIRA, G. H. S.; MANTOVANI, E. C., CORDEIRO, É. A. Estudo comparativo da avaliação de sistemas de irrigação por gotejamento utilizando os métodos propostos por Keller e por Denículi. PNP\&D-café, EMBRAPA Café. Viçosa-MG, p.15. 2004a.

VIEIRA, G.H.S.; MANTOVANI, E.C.; SILVA, J.G.F.; RAMOS, M.M.; SILVA, C.M. Recuperação de gotejadores obstruídos devido à utilização de águas ferruginosas. Revista Brasileira de Engenharia Agrícola e Ambiental, v.8, p.1-6, 2004b. 